\title{
Involving Consumers: The Role of Digital Technologies in Promoting 'Prosumption' and User Innovation
}

\author{
Thierry Rayna $^{1} \cdot$ Ludmila Striukova $^{2}$
}

Received: 2 November 2015 / Accepted: 17 June 2016 / Published online: 5 July 2016

C) The Author(s) 2016. This article is published with open access at Springerlink.com

\begin{abstract}
Since the First Industrial Revolution, consumers have been mainly considered as playing a passive role with regard to production. However, the recent decades have seen a progressive growth in consumer involvement in production processes, for instance, in the form of user innovation, DIY and mass customisation. Yet, it was not until the advent of digital technologies that consumers' input in production processes could become really significant in all dimensions of production (design, manufacturing and distribution). This increased (sometimes leading) role of consumers in production has been referred to as 'prosumption'. While prosumption has so far been mainly significant online (where consumers have arguably taken over the creation and distribution of content), recent advances in digital technologies (mobile networks, 3D printing) have enabled prosumption to reach to world of physical objects, as illustrated by the increased importance of consumer-made goods ('makers' movement) and of the 'sharing economy'. Although prosumption can be highly disruptive to markets, there has not been so far a thorough investigation of the nature of this phenomenon. Yet, understanding this nature is critical to apprehend disruptions. Furthermore, while digital technologies have been acknowledged as a key factor in the rise of prosumption, the exact role of each set of technologies has not yet been studied, which is a problem, as different technologies enable different types of prosumption. The aim of this article is to fill these two gaps. To do so, a framework of prosumption, which encompasses both inputs and outputs of consumer contribution, is introduced. This framework is then applied to multiple case studies, which enables to show how prosumption has evolved and what changes lie ahead.
\end{abstract}

Ludmila Striukova

1.striukova@ucl.ac.uk

Thierry Rayna

trayna@novancia.fr

1 Novancia Business School Paris, 3, rue Armand Moisant, 75015 Paris, France

2 University College London, Gower Street, London WC1E 6BT, UK 
Keywords Prosumption - User innovation - Digital technologies · Sharing economy $\cdot 3 \mathrm{D}$ printing

\section{Introduction}

As a form of Open Innovation, User Innovation has had a growing importance over the past few decades, both in the literature and as a part of firms' strategies. While firms have always used to some extent user input as a source of innovation (Rayna and Striukova 2010), the concepts of 'User Innovation' and 'Lead Users' have gained a widespread acceptance following the seminal works of Eric von Hippel (von Hippel 1976, 1977, 1978, 1986). Yet, both in these works and in the abundant literature on User Innovation that has ensued, user input is generally only considered at the conception stage. Regardless of how inventive they are, users are seen as bound to the firm, because they lack the manufacturing, distribution and commercialisation capabilities that only firms have.

While this might have indeed been the case until the late 1990s, the progressive diffusion of digital technologies (in particular, following the Internet 'boom' of the mid 1990s) has radically and durably changed the relationship between users and firms. Indeed, a common trait of all digital technologies is that that they empower users, and in particular consumers, with the ability to create, replicate, distribute and (in some instances) commercialise (Rayna 2008).

The wide availability of digital technologies means that user innovation is no longer restricted to professional end-users and, indeed, consumers have been increasingly engaged in co-creation activities with firms (Rayna and Striukova 2015). In fact, looking at the massive quantity of User Generated Content available online, one could even argue that consumers have in some cases superseded firms, as they now play a leading role in design, 'manufacturing' and distribution.

As a result of their increasingly active role in the production processes, consumers have progressively become 'prosumers'. Since innovative users are no longer bound to the firms, countless user innovations have taken place independently from the firms and, sometimes, even against the firms' will (Zwass 2010; Rayna and Striukova 2015). As a matter of fact, whether legitimately or not, the number of cases where consumers directly compete with firms (for instance by diffusing innovations that have been rejected by the firm) has sharply increased over the past few years. ${ }^{1}$ Hence, as a consequence of the diffusion of digital technologies, the relationship between firms and users has turned from simple cooperation to (potential) coopetition.

While coopetition between prosumers and firms only used to be prevalent online, the recent advances in digital technologies have led this phenomenon to spread to the rest of the economy. For instance, digital manufacturing technologies, such as 3D printing and additive manufacturing, provide end-users (and progressively consumers) with the ability to manufacture objects. In fact, there have already been numerous cases of users manufacturing and selling improved versions of existing commercial products or items complementing such products. ${ }^{2}$ Such technologies have even given rise to consumer-borne ecosystems around popular products (e.g. Legos, Star Wars). Besides

\footnotetext{
${ }^{1}$ See, for instance, the example of the 'Game of Thrones' smartphone dock, p. 25.

${ }^{2}$ See, for instance, the case of the Square Helper, p. 17.
} 
manufacturing, recent advances in digital technologies have also began to considerably disrupt the service industries (e.g. taxis, holiday rentals), with prosumers starting to supply services in direct competition with businesses, by renting out their cars (or driving people around), their flats, their expertise, or any other asset they might own; the inescapable 'sharing economy' is indeed yet another form of prosumption.

As the prosumer phenomenon is arguably spreading to the whole economy, it is critical to understand better the roots and evolution of this phenomenon. To do so, one has to consider how, and to which extent, digital technologies have given means to consumers to contribute to production processes, and whether such contributions are related to design (when user innovation traditionally takes place), manufacturing or distribution.

To do so, this article introduces an 'input-output' prosumption framework that enables to analyse consumers' involvement in the production process with regard to both the type of input they contribute and the type of contribution (relative to the production process) that is made ('Towards a prosumption framework' section). Then, based on multiple case studies and using a historical approach, this prosumption framework is used to investigate the evolution of the impact of digital technologies on prosumption and user innovation: Sect. 3 discusses user innovation and prosumption in the pre-digital era; Sect. 4 investigates user innovation and prosumption in the early (mid 1990s-mid 2000s) digital era; Sect. 5 studies the impact of Web 2.0 (e.g. social media) technologies on prosumption and user innovation; and Sect. 6 considers the most recent impacts of digital technologies and explores the consequences of user manufacturing (through 3D printers) and of the sharing economy. Finally, Sect. 7 tackles the issue of leveraging prosumption from a firm's perceptive and outlines related good practices.

\section{Towards a prosumption framework}

While the word 'consumer' appeared in the English language some time during the late Middle Ages, ${ }^{3}$ the modern concept of consumer as someone who purchases goods and services for personal use unsurprisingly came into existence in the late eighteenth century, at the time of the First Industrial Revolution. Indeed, mechanisation, and the resulting concentration of means of production it necessarily entailed, meant that for the first time in history, production and consumption of goods and services became largely disconnected. ${ }^{4}$

From then on, the perception of the importance of the role played by consumers in the economy progressively grew, up to a point where after World War II consumption started to be considered as the focal point and driving force of modern economies, which had by then become 'mass consumption societies' (Matsuyama 2002). Yet, while recognised as critically important, the role of consumers was still seen as essentially passive, and even increasingly so, as both consumption choices and volumes

\footnotetext{
${ }^{3}$ At the time, as its French root consumer (i.e., 'burn') implies, it referred to someone who spent recklessly and wasted resources.

${ }^{4}$ As opposed, for instance, to the work on a medieval farm, where people would first produce for themselves and then trade what they did not consume in order to obtain goods or services they did not produce.
} 
of consumption were thought to be triggered by corporations, through advertising (Galbraith 1958, 1967).

Hence, the traditional view of mass consumption society is that firms are in charge of deciding, designing, manufacturing (producing), marketing and distributing goods and services, while the role of consumers is, plainly, to consume. Yet, this ultra-passive view of consumers began progressively to change in the late 1970s because of the success of 'new' business models, which involved some degree of consumer participation (e.g. fast-food restaurants, flat packed furniture).

Taking notice the increasing role of consumers in the production processes through DIY ('do-it-yourself') activities (such as self-service, self-help and self-repair), Toffler (1981) coined the term prosumer, a portmanteau word of 'producer' and consumer. Besides the consumer involvement in production processes through DIY activities (which was already happening at the time), Toffler (1981), considering advances in computing, also foresaw a consumer involvement of in the design of customised products (albeit to a fairly minor extent, i.e. providing measurement for customised clothing or objects). Kotler (1986) developed this idea further and emphasised that progresses in information and communication technologies would soon enable consumers to creatively engage in production processes, through mass customisation (i.e. choosing amongst a range — often wide — of options set by the producers, who then manufacture the products on demand).

While 'DIY' business models certainly picked up during the 1980s, with more firms integrating self-service into their products (e.g. factory outlets, home repairs), it took over 3 decades for the mass customisation foreseen by both Toffler (1981) and Kotler (1986) to take place at a significant scale. Consequently, it is not surprising that, for a while, the prosumer concept seemed all but forgotten in the literature. ${ }^{5}$ Yet, this concept began to regain popularity during the $2000 \mathrm{~s}$, following the advent of Web 2.0 technologies (and, more specifically, social media) in particular.

As noted in Rayna and Striukova (2015), Web 2.0 technologies enable consumers to contribute and share textual and multimedia content over the Internet, with almost no technical knowledge being required. Services such as Facebook, Flickr, YouTube, and Wikipedia, led to a surge of consumer (or user)-generated content available online. As highlighted in Tapscott and Williams (2006) and Ritzer and Jurgenson (2010), it became rapidly clear that in all these services, consumers, and not firms, were actually doing the 'bulk of the work'. Indeed, as noted in Ritzer and Jurgenson (2010):

Prosumption was clearly not invented on Web 2.0, but given the massive involvement in, and popularity of, many of these developments (e.g. social networking sites), it can be argued that it is currently both the most prevalent location of prosumption and its most important facilitator as a 'means of prosumption'.

However, as will be shown in the following sections, prosumption is nowadays far from being restricted to online content and technologies, such as 3D printing and smart

\footnotetext{
${ }^{5}$ In contrast, there was a keener interest during the 1980s and 19990s in the role played by clients — generally in a business to business setting - in service and innovation processes.
} 
electricity grid, have enabled consumers to engage in the production (in the sense of manufacturing) of physical products.

Looking at the literature, it is clear that prosumption can take many different forms, some complex, other much simpler. To fully apprehend this phenomenon, it is thus critical to be able to categorise prosumption activities. Yet, when doing so, a further difficulty arises because two different aspects have to be considered: (1) what the nature of what is contributed by the consumers to the production process is and (2) to which aspect of the production process it is contributed. Hence, the prosumption framework introduced in this article consists of two taxonomies: one related to the prosumption inputs in the production process (Fig. 1), and the other related to its output (Fig. 2).

With regard to inputs, a thorough examination of the various cases of prosumption activities shows that consumers either provide labour (in the sense of work force, as in the case of flat packed furniture), intellectual capital (for those activities where consumer creativity and expertise are required; for instance, customisation), or physical capital (in the case where consumers' own physical assets are used as a part of the production process). Interestingly, some prosumption activities require consumers to combine several types of input. For instance, factory outlets require the consumer to provide labour (i.e. to carry the goods), but also to have (or rent) a car (physical capital). Likewise, contributing to Web 2.0/social media requires both knowledge and creativity (intellectual capital), but also to have an Internet connected device or computer (physical capital).

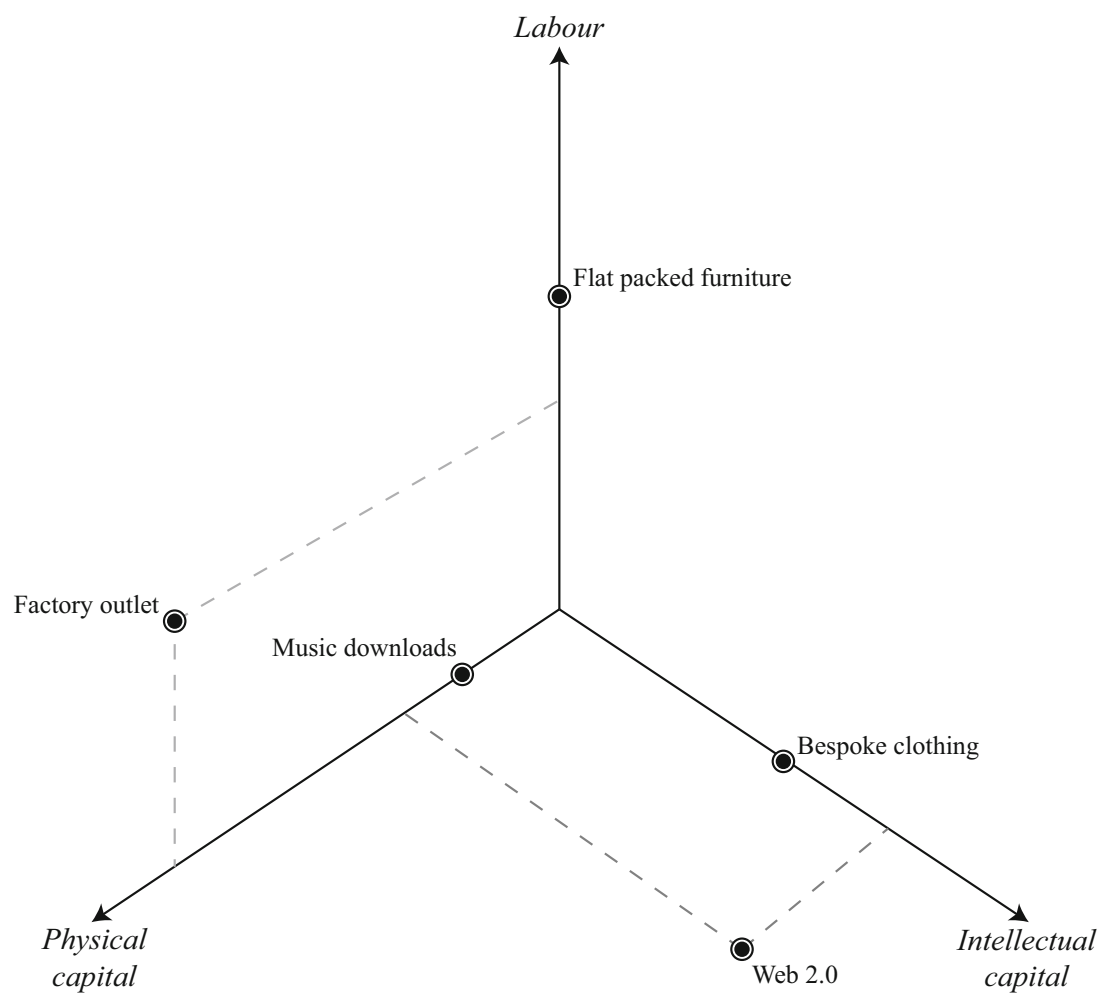

Fig. 1 Taxonomy of prosumer input in the production process 


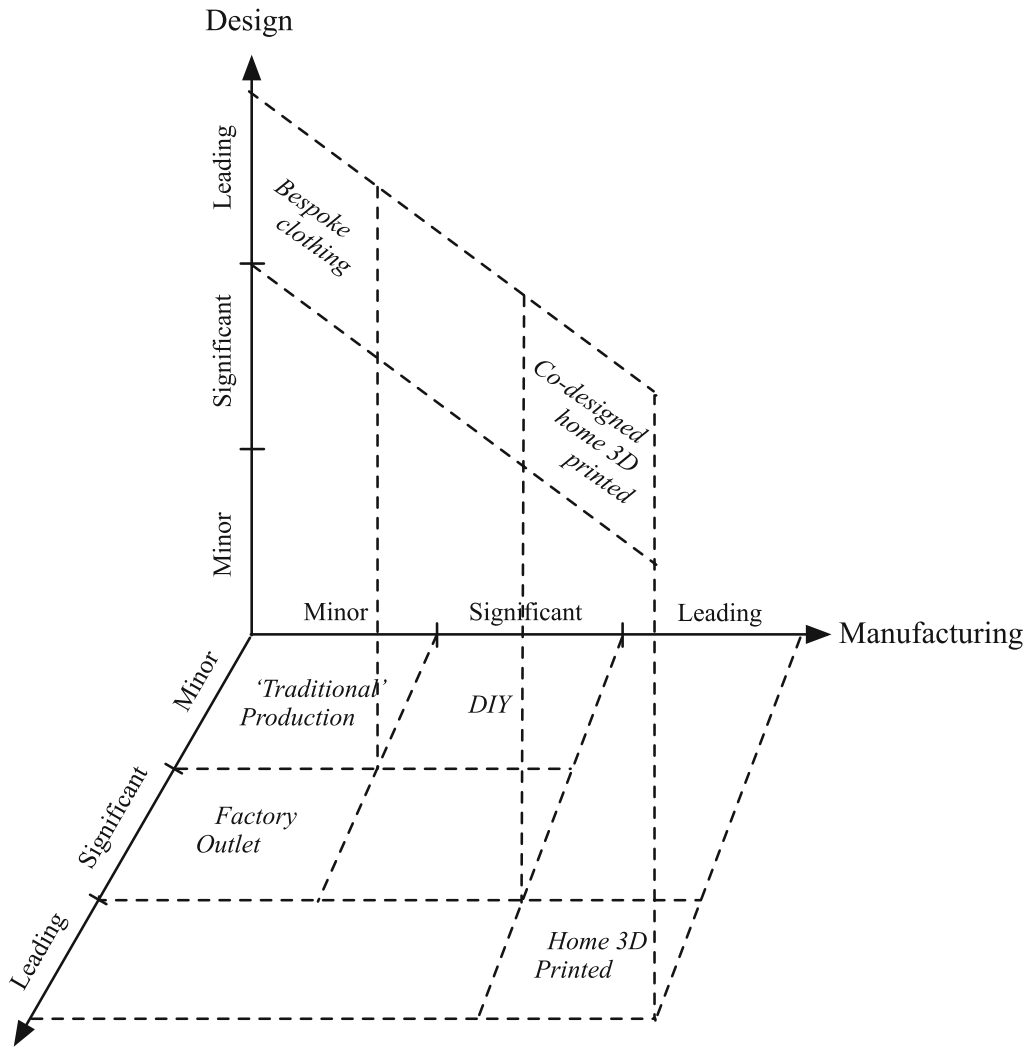

Distribution

Fig. 2 Taxonomy of prosumer output in the production process

Are there prosumption activities that require all three types of inputs? Indeed, there are. For instance, this is typically the case for user innovation when it relates to physical goods. User innovation requires consumers to provide intellectual capital. Consumers engaging in user innovation also need to have tools (physical capital), and building a prototype may also require hard labour, as no machinery is available at prototyping stage. $^{6}$

It could be argued that when consumers take part in production processes, they either contribute 'time' or 'money' (or a mix of both). This is actually reflected in the taxonomy presented in Fig. 1. Indeed, the two axes, labour and intellectual capital, correspond to a contribution related to time (whether 'force' or 'brains'), whereas the third axe, physical capital, relates to money. In this respect, it can be noted that, indeed, in many cases, prosumers face a trade-off between providing time and money (for

\footnotetext{
${ }^{6}$ Though, as will be discussed in the following sections, additive manufacturing/3D Printing technologies enable user innovators to mechanise the prototyping stage.
} 
instance, a wealthier prosumer could pay someone to mount flat packed furniture, whereas a less wealthy prosumer engaging in user innovation would probably build a prototype by hand instead of using a $3 \mathrm{D}$ printer). ${ }^{7}$

As shown in the output taxonomy (Fig. 2), the inputs provided by prosumers can contribute to different parts of the production process. Indeed, prosumers can contribute to design (in its broadest sense, i.e. all that pertains to the conception phase of a product or service), manufacturing (understood here as the reproduction, whether tangible or intangible, of a product or service) and distribution.

Whereas 'traditional' production usually involves fairly little participation from the consumers (i.e. no participation in design, no or fairly little assembly required, involvement in distribution is limited to visiting a local store), other forms of production entail a more significant contribution (Fig. 2). Factory outlets, for instance, require a significant involvement of consumers in distribution, since they need to drive (presumably) further to the factory instead of going to a nearby store. Likewise, DIY (e.g. flat packed furniture) requires consumers to contribute to manufacturing, as they carry out the final assembly of the product. Finally, mass customisation leads to consumers playing a role in design, a role that can range from minor to significant, depending on the number of customisation options offered and the extent of the modification of the product. In some cases (e.g. bespoke clothing), because customisation options available are not set (and possibilities are 'endless'), consumers can even take a leading role in design.

While many examples have been given in the literature, there is currently no clear definition of what prosumption actually is. This is certainly due to the fact that prosumption can take very different forms. Thus, the output taxonomy in Fig. 2 enables to better define what prosumption is.

In the literature, prosumption is considered as a situation where consumers take an active role in productive processes. Yet, even in the most traditional and 'passive' view of consumption, consumers have always played an active role, albeit a minor one, in distribution (e.g. going to the store) and, to an even lesser extent, in manufacturing (e.g. unpacking the product, putting batteries in an electronic device). Thus, based on the taxonomy in Fig. 2, prosumption can be defined as follows:

Proposition 1 Prosumption is defined as a situation where consumers are involved in productive processes in either of the following ways:

- Consumers are involved to any extent in design.

- Consumers are involved significantly in manufacturing.

- Consumers are involved significantly in distribution.

User innovation is defined in von Hippel (1976) as a situation where users take a leading role at the design stage of a product (or service). Users perceive the need for an

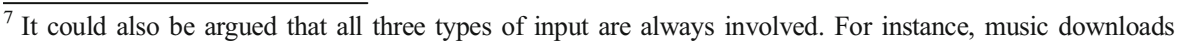
require some labour (to click on the 'download' button) as well as some intellectual capital (to be able to choose which track to download). Likewise, while all necessary tools are provided with Ikea flat packed furniture, scissors (i.e. physical capital) might be required to open the packaging, also while a detailed manual is supplied, some elements of intellectual capital (e.g., being able to read) are also needed. However, in those cases, it is clear that quantity of such inputs used is negligible.
} 
innovation, which leads to an invention. Users then build and test a prototype, which is then commercialised (if successful) by the company. Looking at Proposition 1, it is clear that this definition corresponds very well to one particular case of prosumption: when consumers are (heavily) involved in design, but not significantly in manufacturing and distribution.

Thus, when carried out by consumers (there are, of course, cases when user innovators are not consumers), user innovation is, in fact, a component of prosumption. ${ }^{8}$

Proposition 2 User innovation, when carried out by consumers (i.e. for final consumption purpose), is a form of prosumption related to the design phase of the productive process. In such a case, user innovators are prosumers.

The two frameworks (Figs. 1 and 2) and the two propositions introduced in this section will be used in the following sections to analyse the impact of digital technologies on prosumption and user innovation.

\section{Prosumption in the pre-digital era}

Prosumption in the pre-digital era has been largely touched upon in the previous section. Examples drawn from the literature, in particular Toffler (1981), Kotler (1986) and von Hippel (1976), as well as the related prosumer inputs and outputs they entail, are summarised in Table 1. Looking at these examples, it is clear that they are rather unidimensional, both from the input and the output perspective. The only exception is user innovation, as in the pre-digital era, it generally involved all three types of input.

Indeed, innovating consumers had not only to think but also to carve, solder, cut, etc. with their own tools in order to build a prototype. For instance, when mountain biking began in the early 1970s, existing commercial bikes were not suited to this type usage. As a result, early users created their own bikes out of strong old bike frames (or built new frames by soldering thicker tubes), with balloon tires and motorcycle lever-operated drum brakes (Lüthje et al. 2005). They were therefore using their design (intellectual capital), spare parts and tools (physical capital), as well as labour.

However, the relative level of contribution related to each type of input did essentially depend on the case at hand (for instance, building the prototype might require a significant amount of intellectual capital but little labour or investment in tools). With regard to output, user innovators were in some cases leading the development of new products, while in other cases, they only made fairly minor contributions to design. In all cases, however, pre-digital user innovation was on the output side almost always restricted to design, as users had no means to manufacture (on a large scale) and distribute their innovation and, therefore, had to rely on companies to do so.

\footnotetext{
${ }^{8}$ In contrast, User Innovation carried out by businesses (e.g. the traditional example of scientific instruments used by universities and R\&D labs) is not prosumption.
} 
Table 1 Pre-digital forms of prosumption: prosumers' input and output

\begin{tabular}{|c|c|c|c|c|c|c|}
\hline & \multicolumn{3}{|l|}{ Input } & \multicolumn{3}{|l|}{ Output } \\
\hline & Labour & $\begin{array}{l}\text { Intellectual } \\
\text { capital }\end{array}$ & $\begin{array}{l}\text { Physical } \\
\text { capital }\end{array}$ & Design & Manufacturing & Distribution \\
\hline Flat-packed furniture & Significant & - & - & - & Significant & (Minor) \\
\hline Factory outlet & (Minor) & - & Significant & - & - & Significant \\
\hline $\begin{array}{l}\text { (simple) Mass } \\
\text { customisation }\end{array}$ & - & Minor & - & Minor & - & - \\
\hline Bespoke clothing & - & $\mathrm{M} / \mathrm{S} / \mathrm{L}$ & & $\mathrm{M} / \mathrm{S} / \mathrm{L}$ & - & - \\
\hline User Innovation & $\mathrm{M} / \mathrm{S} / \mathrm{L}$ & $\mathrm{M} / \mathrm{S} / \mathrm{L}$ & $\mathrm{M} / \mathrm{S} / \mathrm{L}$ & $\mathrm{M} / \mathrm{S} / \mathrm{L}$ & - & - \\
\hline
\end{tabular}

\section{Prosumption in the early digital era}

For most consumers in the 'more economically developed countries', the early digital era spanned from the mid-1990s to the mid-2000s. In the mid-1990s, the Internet, but also other forms of digital replication and distribution (e.g. CD/DVD burners), started to become widely available. Yet, as opposed to the Web 2.0 era that ensued, the early digital era was still characterised by rather passive consumption (e.g. consumer would subscribe and read online the encyclopaedia Microsoft Encarta), as the tools enabling to create and distribute digital goods, while available, were rather difficult and tedious to use. $^{9}$

As a matter of fact, in the early part of this digital era, it is even rather hard to find any significant example of prosumption. This began to change in the late 1990s, first with the advent of peer-to-peer network technologies, and then with the availability of (legal) digital downloads.

Interestingly, it is a (consumer) user innovation that unleashed the first wave of digital prosumption. Frustrated by the lack of instant music download (back then, buying music online meant receiving a CD by the mail a couple of days after you ordered it) and taking advantage of the newly released 'MP3' audio compression format, three college teenagers, Shawn Fanning, John Fanning and Sean Parker, developed and released the first largely adopted peer-to-peer network. Napster, which enabled consumers to easily share and download music files from one another, became an instant and massive success. Within a matter of months, Napster reached 80 million users, who arguably set up the first (albeit non-commercial and non-IP compliant) online music distribution service (Gowan 2012). ${ }^{10}$

While Napster was shut down by court order in July 2001 after 2 years of operation, other peer-to-peer sharing protocols (e.g. Kazaa, eMule, BitTorrent), also borne by

\footnotetext{
${ }^{9}$ Publishing a picture online alone would require using a picture editing software (to compress the picture), an HTML editor to write the code of the webpage on which the picture would be displayed, and an FTP client to upload the files to a remote web server.

${ }^{10}$ As a comparison, 15 years later and despite a heavy worldwide advertising campaign, Apple Music only reached 11 million users during its initial 3-month free trial (Byford 2015). Spotify, the music streaming market leader, had as of January 201560 million users, including 15 million paying users (https://news. spotify. com/us/2015/01/12/15-million-subscribers/).
} 
large user communities, rapidly emerged. Unlike Napster, which was restricted to music files, these new protocols could be used to share any kind of digital media (e.g. movies, software, books, pictures) and were far more resilient to court orders.

The rapid emergence and diffusion of the peer-to-peer sharing protocols, carried out in total independence from the industry (and in spite of it), are hallmarks of the impact of digital technologies on user innovation. Unlike in the case of pre-digital user innovation (Table 1), digital technologies enable users to replicate (manufacture) and distribute digital goods without the help of any firm. Quite strikingly, the first significant user innovation of the digital era has been to provide tools (peer-to-peer networking protocols) enabling consumers to independently (and in a totally decentralised manner) replicate and distribute digital goods amongst themselves (whereas, until then, they had to rely on central servers owned by companies).

A couple of years after peer-to-peer networks emerged, the industry, finally perceiving the needs for a legal offering of digital content, began to supply music, films, TV shows, and software over the Internet. This new mode of content delivery made consumers de facto prosumers. Indeed, unlike before, when the goods (e.g. CDs, DVDs), even if ordered online, were manufactured and distributed by the firms (sometimes to the consumer's very door), online digital delivery (whether download or streaming) necessarily means that consumers take part in both manufacturing and distribution. Indeed, their Internet bandwidth is used to 'transport' the goods and their hard drive (or other storage media) to 'fabricate' and store the goods.

Table 2 summarises, with regard to both inputs and output, the three new modes of prosumption enabled by the advent of digital technologies. In particular, in relation to user innovation - 'Napster (software)' - the difference with pre-digital user innovation (Table 1) is striking. The (legal) 'Music Downloads' example shows new mode of consumption where prosumption becomes the norm and where consumers play a significant role in manufacturing and distribution. However, as illustrated by the 'Napster (usage)' example, firms are no longer necessary. In the case of peer-to-peer networks (which are used for both illegal and legal content), prosumers can even play a leading role and completely bypass traditional manufacturing and distribution channels. 11

\section{Prosumption in the Web 2.0 era}

Hence, digital technologies have transformed consumers into prosumers for digital goods. Yet, in the early years of the digital era, prosumption was mainly restricted to manufacturing (in the sense of reproduction) and distribution, because the tools enabling to 'design' (create) digital content were still expensive and rather complex to operate (a legitimately acquired software suite enabling to publish content online would range from around hundred of euros to a couple of thousands).

This changed significantly in the mid-2000s with the advent of Web 2.0 technologies. Unlike their forebears, Web 2.0 online services were such that virtually no additional tool was required to create and publish content online. Whether social media

\footnotetext{
${ }^{11}$ For this particular example, the table displays 'Minor' for labour because of the original and repetitive task of 'ripping' (importing in the computer and converting to MP3) CDs and vinyls.
} 
Table 2 Examples of early digital forms of prosumption: prosumers' input and output

\begin{tabular}{lllllllll}
\hline & \multicolumn{3}{c}{ Input } & \multicolumn{3}{c}{ Output } \\
\cline { 2 - 4 } \cline { 6 - 8 } & Labour & Intellectual capital & Physical capital & Design & Manufacturing & Distribution \\
\hline Napster (software) & - & Leading & Leading & & Leading & Leading & Leading \\
Napster (usage) & (Minor) & - & Leading & & - & Leading & Leading \\
Music downloads & - & - & Significant & - & Significant & Significant \\
\hline
\end{tabular}

(Facebook, Twitter), content sharing platforms (YouTube, Instagram, Flickr), information aggregation and sharing (Wikipedia), these platforms 'moved' the tools of creation from the desktop computers to the Web, thereby making them free of access and much easier to use (complex software could simply not be deployed online, so it had to be simplified and only retain essential features).

As noted in Rayna and Striukova (2015), Web 2.0 technologies have considerably lowered the barriers to user creation and, in fact, many Web 2.0 services derive their value almost exclusively from the content created by users. Yet, while the 'early digital era', discussed in the previous section, was characterised by consumers taking a leading role in manufacturing and distribution, the 'modern' digital era is significantly different. Indeed, far from taking advantage of the prosumption potential provided to consumers by digital technologies, all Web 2.0 services have adopted a central mode of distribution. Of course, consumers still contribute (they need an Internet connected device to consume), but this contribution is far smaller than what could have been done if social media or Wikipedia, for instance, had been hosted on a fully decentralised consumer network.

While this may seem a fairly minor issue, this is a clear example of a deliberate decision not to take advantage of prosumption capabilities. As a result of this decision, consumers in many countries have been experiencing Internet bandwidth issues, because everyone is pulling digital content from a handful of centralised servers. Alas, overcoming this problem requires significant investment: When thousands or millions are watching the same high-definition YouTube video hosted on centralised servers, the bandwidth needed is simply enormous. Yet, at the same time, all these consumers make little (if any) use of their upstream bandwidth, which could be used to share with other consumers the bits of the video that have already been downloaded. This would certainly be a much more efficient and a far less costly way to distribute videos.

This is something that the British BBC understood perfectly well when it launched iPlayer, its Internet streaming catch-up television and radio service, late 2007. Daunted by the enormous investment required to host such a service using centralised servers, BBC decided instead to develop its own peer-to-peer network as the backbone of iPlayer. Hence, when watching a replay of a $\mathrm{BBC}$ programme, consumers would, at the same time, share this video with other consumers willing to watch it. Videos were of course encrypted using a Digital Rights Management (DRM) system, so that users, even though they were distributing the videos, could not save them on their hard drive or share them outside of the iPlayer service. Unfortunately, because of the bad reputation of peer-to-peer networks (irremediably associated with consumers piracy), and despite not a single case of IP infringement taking place with iPlayer, BBC 
removed this feature late 2008 and moved on to a less efficient (and more costly) centralised way of distribution.

Table 3 illustrates the respective prosumers' contributions for these three cases. In the case of social media, the matter is nonetheless slightly more complex. Indeed, while consumers do not physically take part in reproduction (manufacturing) and distribution of content, which is hosted on the companies' servers, they do play a leading role with regard to which content is ultimately consumed (and distributed). Indeed, the more a particular content is 'liked' or shared, the more it is viewed and distributed. Hence, one could consider that, in spite of the centralised hosting, consumers play a leading role, with regard to manufacturing and distribution on social media.

Comparing Tables 2 and 3, one can notice not only a relative 'decrease' in prosumption related to manufacturing and distribution but also greater levels of prosumption at the design stage. In fact, the table could have been filed with examples of online platforms where consumers essentially produce most of the content. Of course, this does not mean that there are no other forms of prosumption, as the BBC example shows. Yet, while technically possible, it does not appear that there are, as yet, examples of (legal) prosumption where consumers are leading with regard to all three aspects of the output.

\section{Prosumption goes offline: 3D printing and sharing economy}

Until recently, and aside from the handful of special cases presented in 'Prosumption in the pre-digital era' section, prosumption was largely thought to be mainly an online phenomenon. Yet, nowadays, prosumption increasingly also happens 'offline'.

One of the reasons for that is the advent of digital manufacturing technologies, such as Additive Manufacturing/3D printing. While these technologies have now existed for a couple of decades, their very high cost (generally tens or hundreds of thousands of euros) has kept them out of hands of consumers. However, the cost of $3 \mathrm{D}$ printers has rapidly decreased over the past few years (prices have been cut tenfold in just 5 years). Nowadays, home 3D printers can be purchased for less than a thousand euros and professional-grade printers for less than 2500 euros (Rayna and Striukova 2016).

These new manufacturing technologies enable consumers to take a leading role of both manufacturing and distribution of physical objects, and there are already countless of examples of prosumption activities that have been enabled by $3 \mathrm{D}$ printing technologies. One of such cases is the Square Helper.

Table 3 Examples of modern digital forms of prosumption: prosumers' input and output

\begin{tabular}{|c|c|c|c|c|c|c|}
\hline & \multicolumn{3}{|l|}{ Input } & \multicolumn{3}{|l|}{ Output } \\
\hline & Labour & Intellectual capital & Physical capital & Design & Manufacturing & Distribution \\
\hline Wikipedia & - & Leading & Significant & Leading & Significant & Significant \\
\hline Social media & - & Leading & Significant & Leading & $\begin{array}{l}\text { Significant } \\
\text { (Leading) }\end{array}$ & $\begin{array}{l}\text { Significant } \\
\text { (Leading) }\end{array}$ \\
\hline BBC iPlayer & - & - & Significant & - & Leading & Leading \\
\hline
\end{tabular}


Chris Milnes, creator of Square Helper, noticed during his 'consumption activities' an issue with the Square smartphone bank card reader that an increasing number of coffee shops and food carts in his neighbourhood were using. When the employees would attempt to swipe the card, the Square card reader (connected to the jack audio plug of the smartphone) would spin, preventing the card's magnetic strip to be read correctly and even potentially damaging the card (Martin 2013). Frustrated by the extra waiting time when paying because of this flaw in the card reader design, Chris Milnes decided to design and build a prototype of a widget that placed between the smartphone and the reader, which would prevent the latter from swivelling.

This looks, so far, like a typical case of prosumption related to user/consumer innovation. Where it gets interesting is that the advent of digital manufacturing technologies has provided this prosumer with manufacturing capabilities. Before the advent of (cheap) 3D printing, prosumers like Chris Milnes would have had no choice but to find a company to manufacture his widget (most likely, in the case of Chris Milnes, he would have contacted the company that makes the Square reader, hopping for his innovation to be integrated in the product line, which it may have not).

Digital manufacturing technologies considerably increase consumers' prosumption capabilities and, instead, Chris Milnes purchased a 3D printer and started to manufacture his widget (which he named 'Square Helper') at home (he calculated that he could build up to $700 \mathrm{U}$ a week), built a simple website with a PayPal shopping cart and started to sell and distribute the widget himself. ${ }^{12}$

However, this kind of 'full-range' prosumption, where consumers are leading in all inputs and outputs, does not necessarily require home manufacturing, as the latter may also be outsourced (just like a firm would). For instance, a consumer (wishing to remain anonymous, but going by the alias 'Autoparis and Me'), user of the Autolib' French car sharing service, got frustrated by the lack of docking station in the car enabling him to use his phone as navigator. This consumer built a prototype, specifically designed for the Autolib' car (the dock clips to the dashboard vents of the car). Once this was done, he uploaded the digital blueprint of the dock he designed on two online 3D printing platforms (Shapeways and Sculpteo), where he outsources the manufacturing and distribution. When someone purchases the smartphone dock on either platform, the dock is then $3 \mathrm{D}$ printed on demand by the platform, and then packaged and shipped by the platform to the client. ${ }^{13,14}$

There are also cases when prosumers outsource the 3D printing manufacturing of physical products they have designed, but do the distribution themselves (for instance, because they wish to include a manual or other complementary items). In all cases, however, when consumers outsource both manufacturing and distribution, this is still prosumption, because consumers are leading manufacturing and distribution (albeit by commission), just like a regular producer would.

The impact of these new digital manufacturing technologies is, however, not limited to the user innovation cases presented above. Indeed, 3D printing technologies also empower consumer to provide services to other consumers (or even firms). 3D Hubs is a perfect example of that. This online platform enables people who would like to $3 \mathrm{D}$

\footnotetext{
12 http://www.squarehelper.com/

${ }^{13} \mathrm{http} / /$ www.shapeways.com/shops/autoparisandme

${ }^{14} \mathrm{http}: / /$ www.sculpteo.com/en/s/fgqnt/
} 
print and do not have a printer to find people around them who have $3 \mathrm{D}$ printers and are willing to print for them for a fee. At this time, over 23,500 'providers' have signed up with 3D Hubs. While some of these providers are professionals equipped with very expensive machines, the vast majority of them are individuals (often arts, design and architecture students, as well as hobbyists) who use the service either to recover the cost of the printer or to supplement their income. 3D Hubs is, in fact, a direct competitor to the leading online 3D printing platforms, such as Shapeways, Sculpteo or i.Materialise (Rayna et al. 2015), and it is a clear example of prosumption where consumers are leading with regard to manufacturing, but also provide the key input (physical capital).

This last example, where owners of 3D printers 'share' (for a fee) their spare capacity with other users, is, in fact, quite reminiscent of what is generally referred to as the sharing economy. Also, occasionally called 'collaborative economy', this concept encompasses platforms, such as Airbnb, ${ }^{15}$ Blablacar, ${ }^{16}$ Uber, ${ }^{17}$ which enable users (generally consumers) to rent out something they own or provide services to each other.

As emphasised in Belk (2014) and Hamari et al. (2015), it is the rise of digital technologies (in particular ICTs) that has enabled the growth of "collaborative consumption'. While it is indeed undeniable that digital technologies have enabled new forms of consumption and services, there is still an on-going debate as to, precisely, what part of this recent phenomenon is actually new. In particular, while this is certainly the most widely used term, there has been a lot of criticism of the sharing economy denomination, which is considered by some as a misnomer, considering that actual sharing seldom happens. Instead, the vast majority of these services do imply financial transactions (Eckhardt and Bardhi 2015).

Consequently, there have been attempts to find an appropriate denomination for this new phenomenon. Eckhardt and Bardhi (2015), for instance, suggested the designation 'access economy', because platforms, such as Airbnb, Uber and Blablacar, provide access to spare capacities, whether of physical goods or people (or both, in the case of Uber). However, it has been argued, rightfully, that providing 'access' to resources is what businesses have been doing all along and, therefore, access economy is not an accurate description of the new phenomenon.

Indeed, if one has a thorough look at the various services that are generally considered as representative of the sharing economy, one cannot help but notice that there is, indeed, nothing really new about the services offered. Often, there is even nothing really new about the way there are offered (e.g. holiday accommodations or taxi rides have been 'rented' through intermediaries before). What is really new is by whom these services are offered: consumers. ${ }^{18}$

As a matter of fact, a close examination of the key examples of the sharing economy reveals that they all mostly relate to prosumption. And this is what is actually new:

\footnotetext{
${ }_{15}$ Airbnb is a platform that enables people to let (often sublet, in the case of a flat) a couch, a room in their home, or even the whole flat).

${ }^{16}$ Blablacar is a platform that connects drivers and passengers willing to travel together between cities and share the cost of the journey.

${ }^{17}$ Uber is a mobile app that enables consumers with smartphones to submit a trip request that is then routed to Uber drivers who use their own car.

${ }^{18}$ Uber, in many countries, offers different types of services: taxi rides operated by professionals (e.g., Uber $\mathrm{X}$ ) and transportation services offered by non-professional individuals (e.g., Uber Pop). It is the latter that is generally thought as being part of the 'sharing economy'.
} 
Digital technologies have enabled to expand offline (i.e. with physical goods) the opportunities of prosumption. In this respect, Belk (2014) considers the sharing economy as the offline extension of the online Web 2.0 phenomenon. Consequently, it would only seem sensible that the phenomenon usually referred to as sharing economy should in fact be named 'prosumer economy', since generalised prosumption is the defining feature of this new phenomenon.

The various examples of offline prosumption mentioned in this section are summarised in Table 4. In the case of consumer innovation, such as Square Helper, consumers have a leading role in all aspects of the output, as well as most of the inputs. In this respect, it can be noted that digital manufacturing technologies enable to substitute capital (intellectual or physical) for labour. Unlike in the 'old fashioned' user innovation described in 'Prosumption in the pre-digital era' section, user innovators nowadays seldom need work force in order to innovate (though they may still use it, if they prefer to).

Platform such as 3D Hubs enable consumers to provide on-demand manufacturing services, in which case they have a leading role in providing the physical capital (i.e. the printer) and, of course, in manufacturing (they might occasionally have to supply intellectual capital to fulfil the service, for instance if the client failed to supply a good enough digital blueprint).

Finally, the prosumption framework introduced in 'Towards a prosumption framework' section can be used to describe contributions to inputs and outputs in the sharing economy. In that case, manufacturing relates to the production of the service (e.g. renting a room, a car drive) and distribution relates to the connection between the supplier of the service and the client. Thus, prosumers who supply services as a part of the sharing economy play a leading role in providing physical capital (their flat, their car). In some cases, the service involves labour (e.g. driving people) and might also involve intellectual capital (e.g. providing an appealing description of a flat for Airbnb). With regard to the output, consumers have a leading role in delivering the service (manufacturing), but only a minor role in distribution, since it is the platform (Airbnb, Uber, etc.) that plays the main role in connecting people.

\section{Overcoming the challenges of leveraging prosumers}

Based on the previous section, it is quite clear that digital technologies have turned prosumption and user innovation from something that was totally under the firms'

Table 4 Examples of physical forms of prosumption: prosumers' input and output

\begin{tabular}{|c|c|c|c|c|c|c|}
\hline & \multicolumn{3}{|l|}{ Input } & \multicolumn{3}{|l|}{ Output } \\
\hline & Labour & Intellectual capital & Physical capital & Design & Manufacturing & Distribution \\
\hline Square Helper & - & Leading & Leading & Leading & Leading & Leading \\
\hline 3DHubs & - & (Minor) & Leading & - & Leading & - \\
\hline Blablacar, Uber Pop & Leading & - & Leading & - & Leading & Minor \\
\hline Airbnb & - & Minor & Leading & Minor & Leading & Minor \\
\hline
\end{tabular}


control into a phenomenon that can take place, both online and offline, in total independence from the firms. In fact, nowadays, digital technologies enable almost anyone to become an entrepreneur and start competing with existing businesses. Consumers have therefore become competitors, and whether they end up cooperating or competing with a firm depends largely on the firm's strategy.

In such a context, 'hearing the voice of the consumers' has turned from something mainly optional into something fundamental. Because they refused to do so, several industries have been heavily disrupted by prosumption (whether 'legal' or not). The recording industry, which was pushing for more expensive higher quality physical formats (e.g. DVD-A, SACD), while most consumers wanted cheaper, lower quality music directly distributed online, is a good example of that. By not listening to consumers, the industry triggered a pandemic of illegal prosumption ('piracy'), which was only curbed (despite numerous attempts) once adequate offering (e.g. Spotify, Deezer, Apple Music) had appeared (Aguiar and Waldfogel 2015). Unfortunately for the recording industry, overlooking (actual or potential) prosumption led to the entry of new competitors that understood much better the needs of the consumers and took consumers' ability to obtain what they needed by themselves as a starting point for their new business models. ${ }^{19}$

Likewise, it can be argued that the so-called 'uberisation' of the economy is in fact caused by a lack of understanding of consumer needs and by a gross underestimation of the prosumption potential. Indeed, it is clear that digital technologies have made, through prosumption, most markets contestable. Contestable markets (Baumol 1982) are characterised by a small number of firms that are forced to operate at nearcompetitive levels (where profits are close to zero) because of the threat of short-term entrants. This occurs when (1) market entry and exit costs are very low, (2) there are no sunk costs and (3) entrants have access to the same technology as incumbents.

Thanks to digital technologies, consumers are often placed in this situation. Unlike a business, they do not need to invest, as they already own the goods (e.g. car, couch or flat, 3D printer). They have virtually no cost of entry or exit (it takes just a couple of minutes to sign up to Blablacar or Airbnb). Finally, they have now access to the same technology as the 'big boys' (Uber, with Uber Pop, provides everyone with central booking platform, just like professional taxis have; Shapeways enables everyone to 3D print with machines that cost hundreds of thousands of euros). Because digital technologies make markets contestable, this renders value capture more challenging, as any attempt to leverage value to a large extent might trigger the entry of prosumers on the market.

However, this is not the only issue, as there are also strong implications for user innovation. In the pre-digital era (and, still, until fairly recently for physical products), firms were entirely in control of the fate of user innovation. If an innovation suggested by users did not fit the firm's strategy, it would simply be disregarded, as it was highly unlikely that the innovator could do anything independently from the firm (especially in the case of a consumer). As was shown in the previous sections, digital technologies

\footnotetext{
${ }^{19}$ Early 2015, in a letter to its shareholders, movie/TV show streaming giant Netflix conceded that its main competitor was in fact Popcorn Time, the peer-to-peer Netflix clone, which in addition to being free of charge also had a greater catalogue than Netflix. http://files.shareholder.com/downloads/NFLX/3874203383x0 x804108/043a3015-36ec-49b9-907c-27960fla7e57/Q4_14_Letter_to_shareholders.pdf
} 
have changed everything: Nowadays, consumer innovators are able to release and diffuse their innovation without any help from the firm.

In the digital realm, a typical example of this is the iOS 'Jailbreak' that has existed almost since the early days of the iOS platform (and despite continuous attempts of Apple to prevent it) and enables users (generally consumers) to introduce features and software that Apple did not accept to include in its operating system (but, occasionally, decided to include at later stage).

Nowadays, similar phenomena do also take place in the 'physical' realm. For instance, in 2013, Fernando Sosa, a fan of the TV show 'Game of Thrones', spent a significant amount of time designing a smartphone charger dock in the shape of the famous throne of the series. As in the case of the Square Helper discussed in 'Prosumption goes offline: 3D printing and sharing economy' section, Fernando Sosa wanted to diffuse his innovation. After a contact with the right holders' (HBO) lawyers, Sosa asked for an official licence and offered to pay HBO a percentage on sales, which was denied. ${ }^{20}$ While, as per HBO's request, Sosa stopped selling the famed dock, the digital blueprint of a very similar object surfaced very shortly afterwards on sharing websites and peer-to-peer networks.

Interestingly, this shows that the market is not just contestable not only with regard to what is produced by the firms but also with regard to all the potential complements and derivatives that are not. If there is a need that is not fulfilled by the firm (e.g. Game of Thrones merchandising), consumers will fulfil it themselves, regardless of whether the firm wants it or not. Whereas before the digital era, a 'void' in the market, whether deliberate or not, would remain void, nowadays, it is more than likely that such a void will be filled by prosumption.

Yet, the challenges caused by prosumption can be overcome by embracing the prosumption phenomenon. As mentioned in Rayna and Striukova (2016), Hasbro has adopted a completely opposite strategy to HBO's for its 'My Little Pony' franchise. Instead of attempting to curb prosumption, Hasbro decided to encourage it, which provided the opportunity to control it. Realising that consumer fans would eventually design, manufacture and attempt to distribute objects inspired by the characters of the franchise, Hasbro, instead of blocking them, gave them a platform to do so.

Hasbro signed a deal with the online 3D printing platform Shapeways, which enables fans to upload and sell objects inspired by the My Little Pony franchise. ${ }^{21}$ Fans can upload any object inspired by the franchise, for as long as it abides some common sense rules (and is actually printable), and sell them at a price of their choice. In return, Hasbro gets a (small) percentage of the sales price and controls what is put for sell.

The resulting objects are arguably of very good quality. ${ }^{22}$ By embracing prosumption instead of fighting it, Hasbro has created an ecosystem that enables them to benefit from the creativity and skills of consumers. And, of course, if any particular of those prosumer objects become highly in demand on Shapeways, nothing prevents Hasbro from making it a part of its regular product line and mass-manufacture it.

\footnotetext{
${ }^{20}$ http://nuproto.com/iThrone.html

${ }^{21}$ Hasbro also offers through Shapeways licences for a couple of other of its franchises, such as DragonVale, Dungeons\&Dragons, GIJoe, Monopoly, Scrabble or Transformers. http://www.shapeways. com/engage/superfanart

${ }^{22}$ See http://www.shapeways.com/superfanart/mylittlepony for examples.
} 
While these are only a couple of examples, there is a clear trend towards a greater (potential or actual) prosumption. Yet, in many cases, prosumers still constitute an untapped resource, although many of them are skilled, educated, very much knowledgeable of their needs and of the needs of others, and also have means (or have access to means) of production (whether design, manufacturing or distribution). While some companies have learned to use 'prosumer power' to their advantage, most do not. Because of that, they face the risk that one day, a priori cooperative consumers become their competitors or that a new entrant that understands how to leverage prosumers wipes these firms out of their own market.

It is thus critical that firms stop considering consumers as a (somewhat) captive herd, but, instead, as coopetitors in a joint ecosystem. Involving all the participants in the ecosystem and ensuring that the benefits of the ecosystem are 'fairly' shared is certainly a challenge that an increasing number of firms will have to face in the near future.

\section{Conclusion}

It is clear that digital technologies have had a major impact on prosumption and user innovation. From a situation where prosumption and user innovation were (generally) initiated by firms and carried out under their full control, digital technologies have progressively made prosumption and consumer innovation ubiquitous and unavoidable.

Yet, prosumption can and does take many forms and each different form comes with different challenges for the firms. It was therefore necessary to understand precisely the nature of each form of prosumption. The framework introduced in 'Towards a prosumption framework' section enables to do so, as illustrated by its application to multiple case studies throughout the article.

One of the insights provided by the use of this framework is that while digital technologies have enabled consumers to be leading with regard to any aspect, whether input (labour, intellectual capital, physical capital) or output (design, manufacturing, distribution), of the production process, the actual form of prosumption that prevails on the market often has a rather minimal involvement of the prosumer (e.g. music is not distributed on peer-to-peer networks, prosumer still needs a company like Blablacar to intermediate). In fact, it is quite likely that in many situations, full-scale prosumption is neither achievable nor desirable.

Yet, prosumption has become a reality and most successful business models integrate, at least to some extent, some form of prosumption. As discussed in 'Overcoming the challenges of leveraging prosumers' section, regardless of the extent to which it happens, prosumption is a force to reckon with, as it not only makes most consumer markets contestable but also enables consumers to fill in gaps left by firms in the market.

For firms, involving prosumers has not only become an obligation, but it can also be a significant source of competitive advantage. Nonetheless, there is a fine line between prosumption benefiting the firm and prosumption undermining the firm. A line that, furthermore, moves over time! As discussed in 'Overcoming the challenges of leveraging prosumers' section, there is undoubtedly a 
shift needed towards ecosystem management, where consumers are no longer seen as a (relatively) captive heard but as legitimate competitors.

Whether actual or potential, the importance and the effect of prosumption in the economy have considerably increased over the past decades. With prosumption reaching the realm of physical objects and services, one could argue that the industry disruptions that have been observed online are about to reach the entire economy. Hence, the question is: are we moving away from a 'digital economy' towards a prosumer economy?

Open Access This article is distributed under the terms of the Creative Commons Attribution 4.0 International License (http://creativecommons.org/licenses/by/4.0/), which permits unrestricted use, distribution, and reproduction in any medium, provided you give appropriate credit to the original author(s) and the source, provide a link to the Creative Commons license, and indicate if changes were made.

\section{References}

Aguiar, L., \& Waldfogel, J. (2015). Streaming reaches flood stage: does Spotify stimulate or depress music sales? Institute for Prospective Technological Studies Digital Economy Working Paper 2015/05, European Commission Joint Research Centre.

Baumol, W. J. (1982). Contestable markets: an uprising in the theory of industry structure. American Economic Review, 72(1), 1-15.

Belk, R. (2014). You are what you can access: sharing and collaborative consumption online. Journal of Business Research, 67(8), 1595-1600.

Byford, S. (2015). Apple Music has a third as many paying subscribers as Spotify. The Verge. Published 20 October 2015 (Retrieved 28 October 2015). http://www.theverge.com/2015/10/20/9572667/apple-musicsubscriber-count-number-paid.

Eckhardt, G. M. and Bardhi, F. (2015). The sharing economy isn't about sharing at all. Harvard Business Review. Published 28 January 2015 (Retrieved 29 October 2015). https://hbr.org/2015/01/the-sharingeconomy-isnt-about-sharing-at-all.

Galbraith, J. K. (1958). The Affluent Society. Houghton Mifflin.

Galbraith, J. K. (1967). The New Industrial State. Princeton University Press.

Gowan, M. (2012). Requiem for Napster. PC World. Published 18 May 2002 (Retrieved 28 October 2015). http://www.pcworld.idg.com.au/article/22380/requiem_napster/.

Hamari, J., Sjöklint, M., \& Ukkonen, A. (2015). The sharing economy: why people participate in collaborative consumption. Journal of the Association for Information Science and Technology. doi:10.1002/asi.23552.

Kotler, P. (1986). The prosumer movement: a new challenge for marketers. Advances in Consumer Research, 13(1), 510-513.

Lüthje, C., Herstatt, C., \& Von Hippel, E. (2005). User-innovators and "local" information: the case of mountain biking. Research Policy, 34(6), 951-965.

Martin, S. (2013). Square Helper: designed and mass manufactured in a home office with a MakerBot. SolidSmack. Published 18 January 2013 (Retrieved 29 October 2015). http://www.solidsmack. com/culture/square-helper-designed-and-manufactured-in-a-home-office-with-a-makerbot/.

Matsuyama, K. (2002). The rise of mass consumption societies. Journal of Political Economy, 110(5), 10351070.

Rayna, T. (2008). Understanding the challenges of the digital economy: the nature of digital goods. Communications \& Strategies, 71, 13-26.

Rayna, T., \& Striukova, L. (2010). Large-scale open innovation: open source vs. patent pools. International Journal of Technology Management, 52(3/4), 477-496.

Rayna, T., \& Striukova, L. (2015). Open innovation 2.0. Is co-creation the ultimate challenge? International Journal of Technology Management, 69(1), 38-53.

Rayna, T., \& Striukova, L. (2016). From rapid prototyping to home fabrication: how 3D Printing is changing business model innovation. Technological Forecasting and Social Change, 102, 214-224.

Rayna, T., Striukova, L., \& Darlington, J. (2015). Co-creation and user innovation: the role of online 3D printing platforms. Journal of Engineering and Technology Management, 37, 90-102. 
Ritzer, G., \& Jurgenson, N. (2010). Production, consumption, prosumption: the nature of capitalism in the age of the digital 'prosumer'. Journal of Consumer Culture, 10(1), 13-36.

Tapscott, D., \& Williams, A. D. (2006). Wikinomics: how mass collaboration changes everything. New York: Portfolio.

Toffler, A. (1981). The third wave. New York: Bantam Books.

von Hippel, E. (1976). The dominant role of users in the scientific instrument innovation process. Research Policy, 5(3), 212-239.

von Hippel, E. (1977). Transferring process equipment innovations from user-innovators to equipment manufacturing firms. R\&D Management, 8(1), 13-22.

von Hippel, E. (1978). A customer-active paradigm for industrial product idea generation. Research Policy, $7(3), 240-266$.

von Hippel, E. (1986). Lead users: a source of novel product concepts. Management Science, 32(7), 791-805.

Zwass, V. (2010). Co-creation: toward a taxonomy and an integrated research perspective. International Journal of Electronic Commerce, 15(1), 11-48. 